DOI: https://doi.org/10.24127/ajpm.v10i2.3542

\title{
ETNOMATEMATIKA: KARAKTERISTIK BATIK BONDOWOSO DI RUMAH PRODUKSI KI RONGGO
}

\author{
Erfan Yudianto $^{1 *}$, Susanto², Toto' Bara Setiawan ${ }^{3}$, Hidayatud Diyanah ${ }^{4}$ \\ 1,2,3,4 Universitas Jember, Jember, Indonesia \\ *Corresponding author \\ E-mail: $\quad$ erfanyudi@unej.ac.id ${ }^{\left.{ }^{*}\right)}$ \\ susantouj@unej.ac.id $^{2)}$ \\ totobarasetiawan@unej.ac.id ${ }^{3)}$ \\ hidayah.math@gmail.com ${ }^{4}$
}

Received 08 February 2021; Received in revised form 28 June 2021; Accepted 06 July 2021

\begin{abstract}
Abstrak
Etnomatematika adalah hubungan antara matematika dan budaya. Penelitian ini bertujuan untuk mendeskripsikan etnomatematika Batik Bondowoso. Penelitian ini menggunakan penelitian kualitatif dengan pendekatan etnografi. Subjek penelitian adalah 3 pengrajin di rumah produksi Batik Kironggo. Pengumpulan data dilakukan dengan observasi, wawancara, dan dokumentasi. Teknik analisis data yaitu dengan cara melakukan observasi lapangan kemudian memberikan beberapa pertanyaan terkait apa saja yang dilakukan oleh ketiga subjek itu di lapangan. Hasil penelitian ini menunjukkan adanya etnomatematika pada batik Bondowoso khususnya di rumah produksi Ki Ronggo berupa titik, garis, sudut, bentuk 2D (persegi, belah ketupat dan lingkaran), persamaan dan transformasi geometri (pergeseran, refleksi, rotasi dan dilatasi).
\end{abstract}

Kata kunci: Batik Bondowoso; etnomatematika; geometri.

\begin{abstract}
Ethnomathematics is a relationship of mathematics and culture. The purpose of this research is to describe the ethnomathematics of Batik Bondowoso. The research using qualitative research with an ethnographic approach. The subjects of this research were 3 craftsmen at the Kironggo Batik production house. Data was collected by observation, interviews, and documentation. The data analysis technique is by conducting field observations and then giving some questions related to what the three subjects did in the field. The results of this study indicate that there are ethnomathematics in batik bondowoso, especially at Ki Ronggo's production house in the form of points, lines, angles, 2D shapes (square, rhombus and circle), equations and geometric transformations (translation, reflection, rotation and dilation).
\end{abstract}

Keywords: Batik of Bondowoso; ethnomathematics; geometry.

This is an open access article under the Creative Commons Attribution 4.0 International License

\section{PENDAHULUAN}

Matematika pada hakekatnya tumbuh dari keterampilan atau aktivitas lingkungan budaya (Suprapto, 2019). Dalam proses pembelajaran secara formal matematika menjadi salah satu pelajaran yang sulit dimengerti, karena sulit menemukan keterkaitan konsep matematika dengan kehidupan sehari- hari. Untuk dapat melihat kaitan matematika dengan budaya di kehidupan sehari-hari, ada suatu ilmu yang menjembatani keduanya yaitu etnomatematika.

Etnomatematika adalah studi tentang ide-ide matematika dari masyarakat tradisional (Putra, Alviyan, Arigiyati, \& Kuncoro, 2021; Swetz, 
2016). Etnomatematika adalah hasil aktivitas suatu suku yang didalamnya terdapat konsep-konsep matematika yang kadang tanpa disadari oleh masyarakat itu sendiri (Zayyadi, 2017). Seperti halnya Indonesia merupakan negara yang memiliki semboyan Bhinneka Tunggal Ika, dimana Indonesia memiliki keberagaman budaya yang bervariasi. Salah satunya adalah batik, batik merupakan kekayaan bangsa Indonesia. Batik adalah hasil kebudayaan asli bangsa Indonesia yang mempunyai nilai tinggi (Astuti, Purwoko, \& Sintiya, 2019). Batik merupakan ekspresi yang memiliki makna simbolis dan nilai estetika yang tinggi bagi masyarakat Indonesia. Keunikan yang indah membentuk karakteristik tersendiri untuk membedakan batik di setiap daerah (Amirullah, Wardoyo, \& Rapitasari, 2019). Hampir setiap daerah di Indonesia memiliki karakteristik batik sendiri-sendiri.

Bondowoso merupakan salah satu daerah penghasil batik di Pulau Jawa tepatnya Provinsi Jawa Timur. Bondowoso memiliki batik khas sejak tahun 1984 dan itu semua harus dilindungi (Kusumaningtyas, 2013). Batik khas Bondowoso pada rumah produksi Batik Sumbersari mengembangkan motif dari berbagai jenis flora dan fauna, namun yang menjadi ciri khas dalam motifnya adalah motif Daun Singkong (Subadyo, 2017). Sanggar batik Magenda juga memproduksi batik khas Bondowoso dengan motif daun singkong sebagai motif utama (Mardliyah, 2016). Batik Bercak Bondowoso memiliki motif kopi dan daun singkong sebagai batik khas Bondowoso (Sitorus, 2017). Batik lukis daun singkong di rumah batik Daweea Bondowoso lebih menonjolkan kearifan lokal berupa daun singkong, dikarenakan Bondowoso terkenal dengan kota tape (Yudianto, et al., 2020). Namun berdasarkan hasil penelitian-penelitian di atas belum ada yang mengungkap batik asli Bondowoso terkait dengan blue fire dan kopi.

Bondowoso yang terkenal dengan produksi tape, sehingga banyak ditemukan pengrajin batik menggunakan tema daun singkong. Padahal, Bondowoso juga memiliki jalan yang melalui lereng gunung ijen. Jalan ini tembus sampai Kabupaten Banyuwangi. Gunung ijen terkenal dengan julukan blue fire dan di sekitar lereng banyak ditemui tanaman kopi. Hal inilah yang sering terlupakan untuk diangkat. Padahal, berdasarkan laporan penelitian-penelitian di atas mengatakan, bahwa untuk membuat bahan ajar diperlukan karakteristik dari objek yang diteliti.

Berdasarkan uraian dari beberapa rumah produksi batik yang ada di Bondowoso memiliki motif dan ciri khas yang berbeda-beda untuk diangkat sebagai motif utama. Oleh karena itu diangkat penelitian terkait dengan karakteristik etnomatematika pada batik khas Bondowoso di rumah produksi Batik Kironggo. Hal ini dikarenakan corak batik di rumah produksi Ki Ronggo memiliki karakter daerah timur Bondowoso yaitu perbatasan dengan Kabupaten Banyuwangi, dimana keindahan alam berupa blue fire hanya dimiliki oleh dua negara di dunia yaitu Islandia dan Indonesia yang berada di Kawah Gunung Ijen (Perbatasan Bondowoso dan Banyuwangi).

\section{METODE PENELITIAN}

Penelitian ini merupakan penelitian kualitatif dengan pendekatan etnografi yang digunakan untuk 
menggambarkan, menjelaskan dan menganalisis konsep atau unsur geometri yang terdapat pada batik khas Bondowoso. Daerah penelitian yang digunakan dalam penelitian ini adalah rumah produksi Batik Kironggo yang berada di Desa Sumbersuko, Kecamatan Klabang, Kabupaten Bondowoso, Jawa Timur. Subjek penelitian ini terdiri dari 3 orang dengan kode $\mathrm{C}, \mathrm{T}$ dan $\mathrm{S}$, dimana $\mathrm{C}$ selaku pemilik serta pembuat pola/desain batik, $\mathrm{T}$ selaku pemilik dan pembatik cap, serta $\mathrm{S}$ selaku pembatik di rumah produksi Batik Kironggo. Penentuan subjek tidak melalui serangkaian tes dan wawancara tetapi mengikuti kriteria yang telah ditetapkan yaitu pemilik/pembuat desain, pembatik cap, dan pembatik di rumah produksi.

Untuk memudahkan dalam mencapai tujuan penelitian, tahap pertama yang telah dilakukan yaitu pendahuluan, pada tahap ini yang dilakukan adalah menentukan daerah dan subjek penelitian. Tahap kedua adalah pembuatan instrumen, yang dilakukan pada tahap ini adalah memvalidasi instrumen pedoman wawancara dan observasi kepada validator, dimana instrumen yang divalidasi dinyatakan sangat valid dengan skor 4,8 skala 5 untuk pedoman wawancara dan 4,9 untuk pedoman observasi. Tahap selanjutnya yaitu pengumpulan data, pada penelitian ini, pengumpulan data diperoleh dengan melakukan observasi, wawancara dan dokumentasi.

Observasi dilakukan dengan mengamati secara langsung proses pembuatanbatik tulis Daun Singkong yang terdapat pada rumah produksi batik Ki Ronggo. Dokumentasi dilakukan pada saat proses pembuatan desain batik. Wawancara dilakukan kepada pembatik terkait dengan pembuatan pola titik, garis dan sudut pada batik dan perhitungan skala di setiap objek batik untuk memperoleh data atau informasi sebanyak dan sejelas mungkin. Tahap berikutnya adalah analisis data, langkah ini dilakukan dengan menyusun data sesuai fokus kajian masalah dan tujuan penelitian. Tahap terakhir penarikan kesimpulan dari hasil analisis data yang telah diperoleh pada tahap-tahap sebelumnya.

Untuk memastikan data yang diperoleh kredibel, maka triangulasi yang yang digunakan adalah triangulasi metode yaitu metode observasi dan tes. Observasi dilakukan pada batik yang telah jadi dan batik yang sedang dikerjakan kemudian dilanjutkan dengan wawancara sebagai konfirmasi terkait dengan hasil konfirmasi. Pedoman wawancara pada penelitian ini dapat untuk melihat aktivitas Mengamati kegiatan pembatik dalam bentuk membuat pola titik dan isen-isen pada batik daun singkong dan kopi dengan indicator konsep titik seperti: (1) Apakah terdapat aturan khusus pada proses pembuatan pola/desain batik (molani)?; (2) Pada tiap isen-isen, apa alas an ibu menambahkan unsur titik di dalamnya? dan (3) Bagaimana cara ibu menorehkan titik-titik tersebut menggunakan canting? Pada aktivitas Mengamati kegiatan pembatik dalam membuat pola garis pada batik daun singkong pada indicator konsep garis seperti: (1) Bagaimana cara ibu membuat garis pada pola batik daun singkong; (2) ala tapa saja yang dibutuhkan?; dan (3) apa alas an ibu membuat pola garis yang melengkung ke kanan dan ke kiri? Dan ketika mengamati kegiatan pembatik dalam membuat pola sudut pada batik daun singkong terdapat pada indikator konsep sudut yaitu Bagaimana cara ibu membuat sudut? 


\section{HASIL DAN PEMBAHASAN}

Berdasarkan hasil observasi pada batik khas Bondowoso dan wawancara terhadap ketiga subjek penelitian di rumah produksi Batik Kironggo diperoleh bahwa dalam proses pembuatan pola/desain dan hasil batik khas Bondowoso terdapat unsur atau konsep geometri yang secara tidak sadar diterapkan oleh para pembatik. Batik khas Bondowoso pada penelitian ini adalah batik tulis daun singkong, batik tulis blue fire, batik tulis Singo ulung dan batik cap Kopi. Unsur atau konsep geometri yang digunakan pada batik khas Bondowoso meliputi: titik, garis, sudut, bangun datar, kesebangunan dan kekongruenan, serta transformasi geometri.

\section{Unsur Titik pada Batik}

Titik tidak dapat didefinisikan namun dapat dideskripsikan. Titik dapat ditentukan letaknya dan berdimensi nol. Titik merupakan bagian dari isen, dimana unsur titik dibuat untuk mengisi kekosongan pada pola batik tertentu. Berdasarkan observasi dan wawancara yang telah dilakukan pada penelitian ini, didapatkan hasil bahwa dalam pembuatan batik khas Bondowoso terdapat pola titik. Titik digambar menggunakan canting isen.

Menurut $\mathrm{S}$ cara membuat isen dengan memanaskan "malam" terlebih dahulu di atas wajan, kemudian menorehkannya di atas kain menggunakan canting isen. Suhu pada "malam" tidak boleh telalu panas dan tidak boleh terlalu dingin, karena jika terlalu panas "malam" akan mblobor dan jika terlalu dinging "malam" akan mengendap. Pembatik menorehkan titik pada kain tanpa adanya pola. Untuk membuat titik dengan ukuran kecil pembatik menorehkan "malam" pada kain dengan waktu yang singkat. Untuk membuat titik dengan ukuran yang lebih besar, pembatik menorehkan "malam" dengan waktu yang lebih lama.

Menurut $C$ titik yang terdapat pada batik tulis Daun Singkong, Kopi, Blue fire dan Singo Ulung memiliki ukuran yang beragam dan jumlahnya tidak sama pada setiap ornamennya. Pada batik tulis Daun Singkong pola titik mengikuti ruas daun singkong dan tersebar pada bagian bawah kain batik. Pada batik cap Kopi pola titik berada diantara garis sejajar, berjejer di antara biji kopi serta membentuk ruas daun singkong. Pola titik juga mengikuti ornamen blue fire, serta tersebar di ruas kanan dan kiri ornamen singo ulung. Pola batik tulis Blue fire dapat dilihat pada Gambar 1.

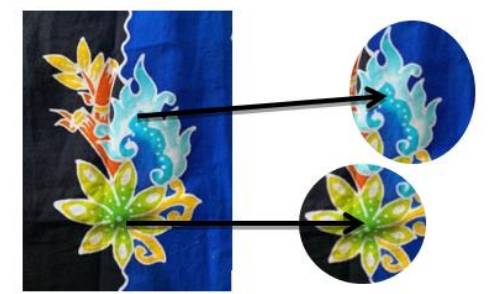

Gambar 1. Pola titik pada batik tulis blue fire

\section{Unsur Garis dan Ruas Garis pada Batik}

Etnomatematika muncul saat pembatik membuat garis. Diberikan dua titik pada garis, selalu terdapat satu titik yang terletak diantara garis tersebut. Berdasarkan observasi dan wawancara yang telah dilakukan dalam penelitian ini, didapatkan hasil bahwa dalam pembuatan batik terdapat unsur garis dan ruas garis. Cara yang digunakan pembatik saat membuat garis dan ruas garis bervariasi, ada yang langsung menggunakan canting dan ada yang menggunakan penggaris saat membuat pola.

Ruas garis termasuk dalam isen dan unsur garis termasuk dalam bagian 
pola tertentu. Ruas garis yang termasuk isen dibuat untuk mengisi ruang kosong dan membuat tampilan batik menjadi lebih indah. Adapun unsur garis yang termasuk dalam bagian pola tertentu dibuat menggunakan penggaris agar mendapatkan hasil yang lurus dan ada juga garis yang dibuat menggunakan penggaris namun setelah dicanting menjadi tidak lurus karena pada proses pencantingan tidak menggunakan penggaris.

Unsur garis dan ruas garis ini terdapat pada pola batik Daun Singkong, Kopi dan Blue fire. Unsur ruas garis yang termasuk dalam bagian isen yaitu ruas garis pada pola batik tulis daun singkong. Ruas garis tersebut tersebar pada bagian ornamen daun singkong. Ruas garis yang terdapat pada ornamen daun singkong berukuran kecil. Menurut $\mathrm{C}$ dan $\mathrm{T}$ terdapat garis yang perlu digambar menggunakan penggaris agar lurus yakni pada batik blue fire dan Kopi. Unsur garis yang terdapat pada pola batik Kopi adalah garis lurus yang saling sejajar dan ruas garis lurus dengan kemiringan tertentu, sedangkan unsur garis yang terdapat pada pola blue fire adalah garis vertikal dan horizontal. Pola garis dan ruas garis dapat dilihat pada Gambar 2 dan Gambar 3.

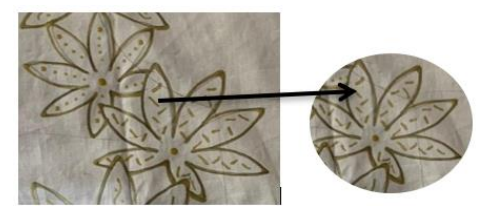

Gambar 2. Pola ruas garis pada batik tulis daun singkong

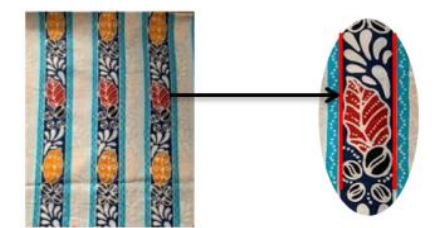

Gambar 3. Pola garis pada batik cap kopi

\section{Konsep Sudut pada Batik}

Sudut didefinisikan sebagai pertemuan dua sinar yang memiliki titik pangkal yang sama. Sebuah sudut yang berukuran kurang dari $90^{\circ}$ disebut sudut lancip. Sudut yang memiliki ukuran tepat $90^{\circ}$ disebut sudut siku-siku. Jika ukuran sudut antara $90^{\circ}$ dan $180^{\circ}$, maka sudut tersebut dinamakan sudut tumpul. Sudut yang berukuran tepat $180^{\circ}$ adalah sudut berpelurus. Sudut yang memiliki ukuran antara $180^{\circ}$ dan $360^{\circ}$ disebut sudut refleks.

Berdasarkan observasi dan wawancara yang telah dilakukan, etnomatematika muncul pada saat pembatik membuat pola sudut pada desain batik khas Bondowoso. Pada hasil batik khas Bondowoso yaitu batik daun singkong, kopi dan blue fire terdapat konsep sudut. Namun tidak ditemukan konsep sudut pada batik Singo Ulung. Konsep sudut terbentuk dari dua garis yang bertemu pada satu titik pangkal yang sama. Terlihat pada batik tulis daun singkong, garis lurus dengan kemiringan tertentu memiliki titik pangkal yang sama. Sudut yang dihasilkan dari kedua garis tersebut adalah sudut lancip (sudut yang berukuran kurang dari $90^{\circ}$ ). Jenis sudut ini juga terdapat pada batik cap Kopi bagian (a) pada pola batik blue fire dan kopi bagian, (b) juga terdapat konsep sudut siku-siku (sudut yang memiliki ukuran $90^{\circ}$ ). Menurut $\mathrm{C}$ dan $\mathrm{S}$ ornamen tersebut digambar sesuai pola yang sudah dibuat dan tidak memperhitungkan besar sudutnya. Pola sudut dapat dilihat pada Gambar 4.

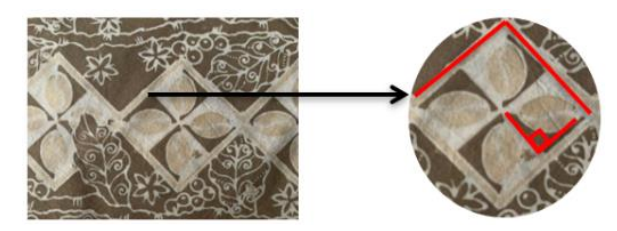

Gambar 4. Pola sudut pada batik cap kopi 
DOI: https://doi.org/10.24127/ajpm.v10i2.3542

\section{Konsep Bangun Datar pada Batik}

Berdasarkan hasil observasi dan wawancara pada penelitian ini, etnomatematika muncul pada saat pembatik membuat pola bangun datar pada desain batik. Bangun datar yang terdapat pada penelitian ini adalah segitiga, segiempat dan lingkaran. Segitiga merupakan bangun datar yang dibatasi tiga sisi tertutup (Gustafson \& Frisk, 1991). Segitiga yang terdapat pada batik tulis daun singkong adalah segitiga lancip. Bangun segitiga terdapat pada batik tulis daun singkong, dimana bangun segitiga tersebut digunakan sebagai isen. $\mathrm{S}$ mengatakan bahwa pada pembuatan bangun segitiga tidak melakukan pengukuran.

Segi empat yang dimaksud adalah belah ketupat dan persegi. Belah ketupat adalah jajargenjang dengan dua sisi yang berdekatan kongruen (Alexander \& Koeberlein, 2014). Jajargenjang adalah segi empat dengan dua pasang sisi yang berhadapan sejajar dan sama panjang. Persegi adalah belah ketupat yang memiliki sudut siku-siku. Bangun belah ketupat terdapat pada batik cap Kopi, sedangkan bangun persegi terdapat pada batik Blue fire. Subjek C menyebutkan belah ketupat sebagai wajik dan persegi sebagai kotak. Untuk membuat bangun belah ketupat dan persegi tersebut pembatik menggunakan penggaris agar lurus dan rapi.

Lingkaran adalah himpunan titiktitik yang memiliki jarak sama dari titik tertentu yang disebut titik pusat, dan jarak dari titik pusat ke titik pada lingkaran disebut jari-jari (Alexander \& Koeberlein, 2014). Pola lingkaran terdapat pada batik cap Kopi dan batik tulis Singo ulung. Subjek T mengatakan bahwa untuk membuat lingkaran pada batik cap kopi, pembatik tidak mengitung diameternya. Untuk membuat lingkaran pada batik tulis
Singo Ulung, C mengukur diameternya karena dari lingkaran tersebut dibagi menjadi beberapa bagian untuk diisi ornamen. Pola bangun datar terdapat pada Gambar 5 dan Gambar 6.

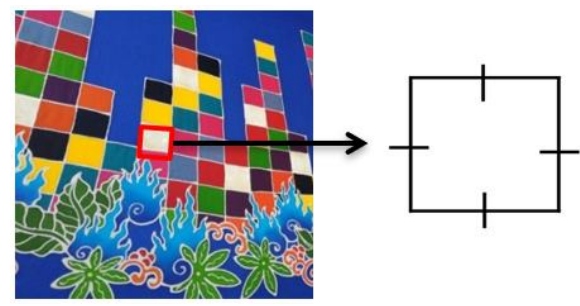

Gambar 5. Pola bangun datar pada batik tulis blue fire

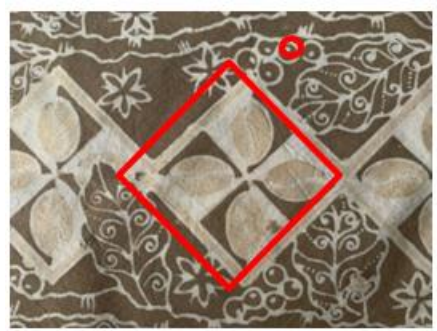

Gambar 6. Pola bangun datar pada batik cap kopi

\section{Konsep Kesebangunan dan Kekongruenan pada Batik}

Apabila dua bangun geometri memiliki bentuk yang sama maka dua bangun tersebut dikatakan sebangun. Namun, apabila dua bangun geometri memiliki bentuk yang sama, semua sisi dan sudut yang bersesuaian memiliki ukuran yang sama, maka kedua bangun tersebut dikatakan kongruen (Alexander \& Koeberlein, 2014). Berdasarkan hasil observasi dan wawancara yang telah diakukan, terdapat konsep kesebangunan dan kekongruenan pada pola batik daun singkong, kopi, blue fire dan Singo ulung. Konsep kesebangunan pada batik daun singkong dapat dilihat pada ornamen daun singkong, biji kopi dan ukel-ukel. Pada batik kopi konsep kesebangunan dapat ditemukan pada biji kopi. Pada batik blue fire dapat konsep kesebangunan terdapat pada 
ornamen blue fire, dan pada batik Singo ulung terdapat pada ornamen kepala singo. Pada ornamen-ornamen tersebut satu ornamen tampak memiliki bentuk yang sama, namun memiliki ukuran yang berbeda, ada yang diperbesar, diperkecil dan sebanding atau mirip. Menurut $\mathrm{C}$ dan $\mathrm{S}$ ornamen-ornamen tersebut sengaja dibuat dengan ukuran besar dan kecil agar terlihat lebih indah. Untuk membuat ornamen-ornamen tersebut pembatik menggunakan cara perkiraan dan blat (duplikasi).

$$
\text { Konsep kekongruenan dapat }
$$
dilihat pada ornamen yang dibuat menggunakan cap. Ukuran dan bentuk dari ornamen tersebut sama. Konsep kekongruenan terdapat pada pola batik cap kopi. Subjek T selaku pembatik cap mengatakan bahwa "untuk membuat ornamen tersebut dengan cara memindahkan canting cap ke posisi yang diinginkan, baik di sebelah kanan, kiri, atas ataupun bawah". Pola kesebangunan dan kekongruenan dapat dilihat pada Gambar 7 dan Gambar 8.

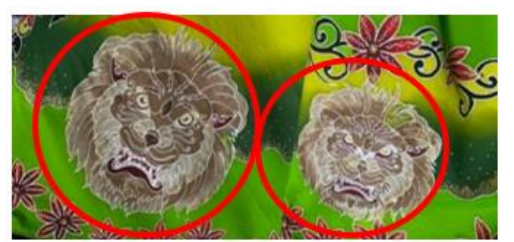

Gambar 7. Pola kesebangunan pada batik tulis singo ulung

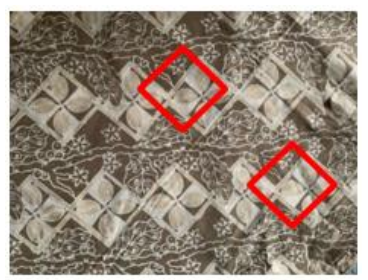

Gambar 8. Pola kekongruenan pada batik cap kopi

\section{Konsep Transformasi Geometri pada Batik}

Konsep transformasi geometri yang terdapat pada batik tulis Singo ulung antara lain translasi (pergeseran), refleksi (pencerminan), rotasi (perputaran) dan dilatasi.

\section{Translasi}

Translasi (pergeseran) merupakan salah satu bentuk transformasi yang bertujuan memindahkan semua titik suatu bangun dengan jarak tertentu. Berdasarkan hasil observasi dan wawancara yang telah dilakukan, etnomatematika muncul pada saat pembatik membuat pola/desain batik yang di dalamnya terdapat konsep translasi atau pergeseran. Konsep translasi ditemukan pada pola batik tulis Daun singkong, blue fire, Singo ulung dan kopi. Pola-pola batik tersebut memiliki bentuk, ukuran dan jarak pada satuan tertentu. Subjek C, T dan S mengatakan bahwa beberapa cara yang digunakan untuk memindahkan motif, diantaranya dengan cara perkiraan dan blat. Menurut $\mathrm{C}$ dan $\mathrm{T}$ untuk cara perkiraan, biasanya pembatik hanya memperkirakan jarak antar ornamen yang satu dengan ornamen lainnya.

Subjek S mengatakan bahwa untuk pembatik pemula, biasanya menggunakan bantuan lidi atau kertas yang dilipat untuk menentukan perkiraan jarak antar ornamen. Untuk cara blat, mengatakan bahwa pembatik membuat satu pola pada selembar kertas terlebih dahulu kemudian menjiplaknya pada kain, sehingga gambar yang dihasilkan memiliki bentuk dan ukuran yang sama. Pola translasi dapat dilihat pada Gambar 9.

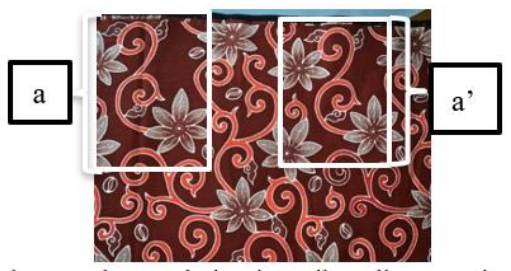

Gambar 9. Pola translasi pada batik tulis daun singkong 
DOI: https://doi.org/10.24127/ajpm.v10i2.3542

\section{Refleksi}

Refleksi merupakan bentuk transformasi geometri yang memindahkan setiap titik di bidang dengan menggunakan sifat bayangan cermin dari titik-titik yang dipindahkan. Sifat dari bayangan benda yang dibentuk oleh pencerminan antara lain bentuk dan ukuran dari bayangan suatu bangun yang dicerminkan sama dengan bangun aslinya; jarak bayangan ke cermin sama dengan jarak cermin ke benda aslinya; bayangan suatu bangun pada cermin saling berhadapan dengan bangun aslinya (Albab, Hartono, \& Darmawijoyo, 2017; Fauzi \& Lu'luilmaknun, 2019; R. Y. Putra, Wijayanto, \& Widodo, 2020; Yanti \& Haji, 2019; Yudianto, Febriyanti, Sunardi, Sugiarti, \& Mutrofin, 2021).

Berdasarkan hasil observasi dan wawancara yang telah dilakukan, diketahui bahwa etnomatematika muncul pada saat pembatik membuat pola/desain batik dimana di dalamnya terdapat konsep refleksi atau pencerminan. Konsep refleksi dapat dilihat pada pola batik tulis Daun singkong, blue fire dan Singo ulung. Pola batik yang mengandung konsep refleksi memiliki bentuk dan ukuran yang sama pada bagian kanan dan kirinya serta terlihat berhadapan pada suatu simetri tertentu (Ayuningtyas \& Setiana, 2019; Hidayatulloh \& Mirza Hariastuti, 2018).

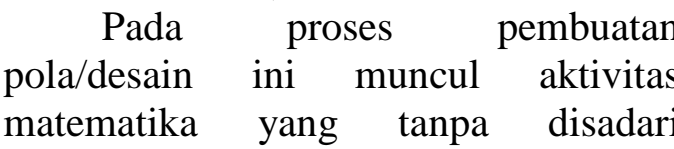
dilakukan oleh pembatik. Subjek C mengatakan bahwa terdapat teknik khusus dalam pembuatan motif tersebut, yaitu dengan membuat satu bagian terlebih dahulu di kertas HVS atau manila kemudian melipat kertas tersebut menjadi dua bagian kemudian menjiplak di sisi sebelahnya sehingga sisi kanan dan kiri memiliki bentuk dan ukuran yang sama seperti tampak dicerminkan. Refleksi yang digunakan adalah refleksi terhadap sumbu-Y, artinya kertas yang digunakan untuk membuat pola dilipat ke kiri atau ke kanan. Pola refleksi pada batik khas Bondowoso dapat dilihat pada Gambar 10.

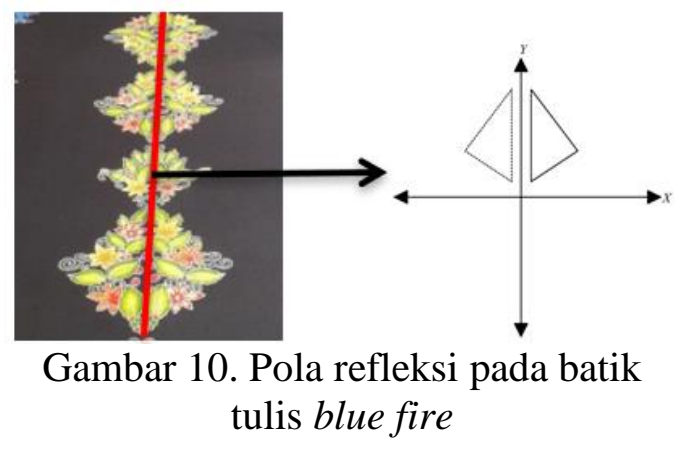

\section{Rotasi}

Rotasi (perputaran) adalah salah satu jenis transformasi memutar setiap titik pada gambar dengan sudut dan arah tertentu terhadap titik yang tetap. Titik tetap disebut pusat rotasi. Bayangan dan bangun asli dalam suatu rotasi selalu kongruen (Albab et al., 2017; Dosinaeng et al., 2020; Hardiani \& Putrawangsa, 2019; Yanti \& Haji, 2019). Arah rotasi menentukan suatu rotasi. Sudut putarnya negatif, jika searah dengan perputaran jarum jam. Sudut putarnya positif, jika berlawanan arah dengan perputaran jarum jam.

Berdasarkan hasil observasi dan wawancara yang telah dilakukan dalam penelitian ini, diketahui bahwa etnomatematika muncul pada saat pembatik membuat pola/desain batik yang di dalamnya terdapat konsep rotasi. Konsep rotasi pada batik khas Bondowoso yaitu pada pola batik Kopi dan Singo ulung. Subjek $C$ dan $T$ mengatakan bahwa tidak menghitung perputarannya. Pada ornamen Singo ulung tampak membentuk bangun 
setengah lingkaran yang berputar dengan kemiringan tertentu. Menurut $\mathrm{C}$ cara pembuatan pola tersebut yaitu dengan membuat lingkaran kemudian membagi menjadi beberapa bagian sehingga antar ornamen memiliki jarak yang sama. Pola rotasi pada batik khas Bondowoso dapat dilihat pada Gambar 11.

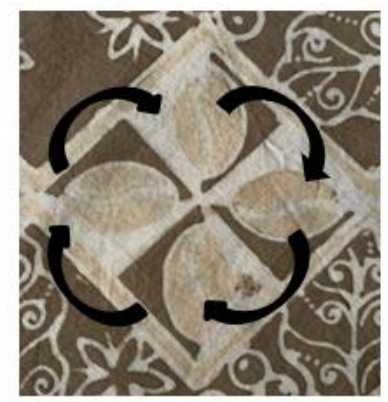

Gambar 11. Pola rotasi pada batik cap kopi

\section{Dilatasi}

Dilatasi merupakan perkalian dari koordinat tiap-tiap titik ada suatu bangun datar dengan faktor skala sebesar $k$. Faktor skala menentukan apakah suatu dilatasi merupakan perbesaran atau pengecilan (Albab et al., 2017; Firdaus \& Hodiyanto, 2019; Yanti \& Haji, 2019). Pada dasarnya konsep dilatasi sama dengan konsep kesebangunan. Bangun geometri dikatakan sebangun jika bangun geometri tersebut memiliki bentuk yang sama serta mengalami perubahan ukuran baik diperbesar ataupun diperkecil.

Berdasarkan hasil analisis data pola batik khas Bondowoso mengandung konsep dilatasi. Konsep dilatasi tampak pada ornamen daun singkong, biji kopi, dan kepala singo. Ornamen-ornamen tersebut memiliki bentuk yang sama namun ukuran dari ornamen tersebut berbeda, ada yang diperbesar ataupun diperkecil. Ornamen tersebut dibuat dengan ukuran yang berbeda agar terlihat indah. Subjek C dan $\mathrm{S}$ mengatakan untuk membuat ornamen tersebut, pembatik menggunakan cara perkiraan dan cara blat. Berdasarkan hasil penelitian, terdapat kesesuaian antara tinjauan pustaka dengan hasil penelitian bahwa pada batik khas Bondowoso terutama pada batik Daun Singkong, Kopi dan Singo Ulung. Pola dilatasi pada batik khas Bondowoso dapat dilihat pada Gambar 7.

\section{KESIMPULAN DAN SARAN}

Etnomatematika muncul pada saat pembatik membuat pola/desain dan pada hasil batik khas Bondowoso terdapat unsur titik dan ruas garis serta konsep sudut, bangun datar (segitiga, segiempat dan lingkaran), kesebangunan dan kekongruenan, transformasi geometri (translasi, refleksi, rotasi dan dilatasi). Pada saat proses pembuatan unsur atau konsep geometri pembatik menggunakan cara pengukuran atau cara perkiraan. Jadi implikasi dari penelitian ini yaitu pembatik lebih mengerti kegunaan matematika dalam membuat pola dan mengukur apa yang hendak dibuat, sehingga tidak coba-coba atau prediksi lagi dalam membuat pola dan mengukur batik yang akan diproduksi.

Adapun saran untuk bahan penelitian selanjutnya yaitu menggali lebih dalam unsur atau konsep matematika yang terkandung dalam proses pembuatan batik ataupun hasil dari batik. Membuat pertanyaan yang lebih jelas dan rinci agar memperoleh lebih banyak informasi yang sesuai dengan tujuan penelitian. Diharapkan adanya pengembangan motif yang berkaitan dengan konsep atau bangun geometri. 


\section{DAFTAR PUSTAKA}

Albab, I. U., Hartono, Y., \& Darmawijoyo, D. (2017). Kemajuan Belajar Siswa Pada Geometri Transformasi Menggunakan Aktivitas Refleksi Geometri. Jurnal Cakrawala Pendidikan, 3(3), 338-348. https://doi.org/10.21831/cp.v3i3.23 78

Alexander, D. C., \& Koeberlein, G. M. (2014). Elementary Geometry for College Students (Fifth Edit; S. Williams, Ed.). Belmont USA: United States Copyright.

Amirullah, A., Wardoyo, T., \& Rapitasari, D. (2019). Peningkatan Kualitas Batik Tulis Motif Tajung di Kelurahan Polagan Sampang Menggunakan Bahan Pewarna Alam Mangrove. JPP IPTEK (Jurnal Pengabdian Dan Penerapan IPTEK), 3(2), 113-126. https://doi.org/10.31284/j.jppiptek.2019.v3i2.683

Astuti, E. P., Purwoko, R. Y., \& Sintiya, M. W. (2019). Bentuk Etnomatematika Pada Batik Adipurwo Dalam Pembelajaran Pola Bilangan. Journal of Mathematics Science and Education, 1(2), 1-16. https://doi.org/10.31540/jmse.v1i2. 273

Ayuningtyas, A. D., \& Setiana, D. S. (2019). Pengembangan Bahan Ajar Matematika Berbasis Etnomatematika Kraton Yogyakarta. AKSIOMA: Jurnal Program Studi Pendidikan Matematika, $\quad 8(1)$. https://doi.org/10.24127/ajpm.v8i1. 1630

Dosinaeng, W. B. N., Lakapu, M., Jagom, Y. O., Uskono, I. V., Leton, S. I., \& Djong, K. D. (2020). Etnomatematika Untuk
Siswa Sekolah Menengah: Eksplorasi Konsep-Konsep Geometri pada Budaya Suku Boti. AKSIOMA: Jurnal Program Studi Pendidikan Matematika, 9(3), 739. https://doi.org/10.24127/ajpm.v9i3. 2900

Fauzi, A., \& Lu'luilmaknun, U. (2019). Etnomatematika pada Permainan Dengklaq sebagai Media Pembelajaran Matematika. AKSIOMA: Jurnal Program Studi Pendidikan Matematika, 8(3), 408. https://doi.org/10.24127/ajpm.v8i3. 2303

Firdaus, M., \& Hodiyanto, H. (2019). Eksplorasi Etnomatematika Islami pada Tradisi Makan Besaprah. AKSIOMA: Jurnal Program Studi Pendidikan Matematika, 8(3). https://doi.org/10.24127/ajpm.v8i3. 2385

Gustafson, R. D., \& Frisk, P. D. (1991). Elementary Geometry (Third). United States of America: Simultaneously.

Hardiani, N., \& Putrawangsa, S. (2019). Etnomatematika: Tradisi Pengukuran Masyarakat Suku Sasak dan Potensi Pengintegrasiannya dalam Pembelajaran Matematika. AKSIOMA: Jurnal Program Studi Pendidikan Matematika, 8(1). https://doi.org/10.24127/ajpm.v8i1. 1814

Hidayatulloh, N., \& Mirza Hariastuti, R. (2018). Kajian Etnomatematika Angklung Paglak Banyuwangi. 7(3), 380-389.

Kusumaningtyas, R. F. (2013). Perlindungan Hak Cipta Atas Motif Batik Sebagai Warisan Budaya Bangsa. Pandecta: Jurnal Penelitian Ilmu Hukum (Research Law Journal), 6(2). 
DOI: https://doi.org/10.24127/ajpm.v10i2.3542

https://doi.org/10.15294/pandecta. v6i2.2337

Mardliyah, W. (2016). Motif batik daun singkong di sanggar batik Magenda Kecamatan Tamanan Kabupaten Bondowoso. Universitas Negeri Malang.

Putra, R. y, Alviyan, D. N., Arigiyati, T. A., \& Kuncoro, K. S. (2021). Etnomatematika pada bangunan Umbul Binangun Taman Sari dalam aktivitas pembelajaran matematika. Ethnomathematics Journal, 2(1). Retrieved from https://journal.uny.ac.id/index.php/ ethnomath/article/view/36081

Putra, R. Y., Wijayanto, Z., \& Widodo, S. A. (2020). Etnomatematika: Masjid Soko Tunggal Dalam Pembelajaran Geometri 2D. Jurnal Riset Pendidikan Dan Inovasi Pembelajaran Matematika (JRPIPM).

https://doi.org/10.26740/jrpipm.v4 n1.p10-22

Sitorus, V. (2017). Perlindungan Hukum terhadap Hak Cipta atas Motif Batik Bercak Bondowoso. Universitas Jember.

Subadyo, H. A. T. (2017). Pengembangan Motif Batik Bondowoso Sebagai Ekspresi Akulturasi Budaya. Jurnal Pengabdian Masyarakat Universitas Merdeka Malang, 1(1). https://doi.org/10.26905/abdimas.v $1 \mathrm{i} 1.1161$

Suprapto, N. S. (2019). Pengembangan Pembelajaran Matematika dengan Pendekatan Etnomatematika Berbasis Budaya Lokal Kudus. Jurnal Pendidikan Matematika, 2(2), 123-144.

Swetz, F. (2016). Ethnomathematics: A Multicultural View of Mathematical Ideas. Mathematical
Association of America, 23(4), 353-355.

Yanti, D., \& Haji, S. (2019). Studi Tentang Konsep-Konsep

Transformasi Geometri pada Kain Besurek Bengkulu. JNPM (Jurnal Nasional Pendidikan Matematika), $3(2)$, 265. https://doi.org/10.33603/jnpm.v3i2 .1744

Yudianto, E., Febriyanti, R. A., Sunardi, S., Sugiarti, T., \& Mutrofin, M. (2021). Eksplorasi etnomatematika pada Masjid Jami' Al-Baitul Amien Jember. Ethnomathematics Journal, 2(1), 11-20. https://doi.org/10.21831/ej.v2i1.36 329

Yudianto, E., Susanto, S., \& Priciliya, S. (2020). Etnomatematika pada Batik Lukis Daun Singkong di Rumah Produksi Daweea Batik Bondowoso. Jurnal Elemen, 6(2), 199-210.

https://doi.org/10.29408/jel.v6i2.20 02

Zayyadi, M. (2017). Eksplorasi Etnomatematika pada Batik Madura. EIgma, 2(2), 35-40. 